This item was submitted to Loughborough's Research Repository by the author.

Items in Figshare are protected by copyright, with all rights reserved, unless otherwise indicated.

\title{
Olympic news and attitudes towards the Olympics: a compositional time- series analysis of how sentiment is affected by events
}

PLEASE CITE THE PUBLISHED VERSION

http://dx.doi.org/10.1080/02664763.2013.868417

\section{PUBLISHER}

(C) Taylor \& Francis

\section{VERSION}

AM (Accepted Manuscript)

\section{PUBLISHER STATEMENT}

This work is made available according to the conditions of the Creative Commons Attribution-NonCommercialNoDerivatives 4.0 International (CC BY-NC-ND 4.0) licence. Full details of this licence are available at: https://creativecommons.org/licenses/by-nc-nd/4.0/

\section{LICENCE}

CC BY-NC-ND 4.0

\section{REPOSITORY RECORD}

Dawson, Peter, Paul M. Downward, and Terence C. Mills. 2019. "Olympic News and Attitudes Towards the Olympics: A Compositional Time-series Analysis of How Sentiment Is Affected by Events". figshare. https://hdl.handle.net/2134/19908. 


\title{
Olympic news and attitudes towards the Olympics: A compositional time-series analysis of how sentiment is affected by events
}

\author{
Peter Dawson ${ }^{\mathrm{a}^{*}}$, Paul Downward ${ }^{\mathrm{b}}$ and Terence C. Mills ${ }^{\mathrm{c}}$
}

${ }^{a}$ School of Economics, University of East Anglia, Norwich Research Park, Norwich, Norfolk, UK

b School of Sport, Exercise and Health Sciences, Loughborough University, Leicestershire, UK

${ }^{\mathrm{c}}$ School of Business and Economics, Loughborough University, Leicestershire, UK

* Corresponding Author. Email: Peter.Dawson@uea.ac.uk 


\begin{abstract}
Sentiment affects the evolving economic valuation of companies through the stock market. It is unclear how 'news' affects the sentiment towards major public investments like the Olympics. In this paper we consider, from the context of the preevent stage of the $30^{\text {th }}$ Olympiad, the relationship between attitudes towards the Olympics and Olympic-related news; specifically the bad news associated with an increase in the cost of provision, and the good news associated with Team GB's medal success in 2008. Using a unique data set and an event-study approach that involves compositional time-series analysis, it is found that 'good' news affects sentiments much more than 'bad' but that the distribution of such sentiment varies widely. For example, a much more pronounced effect of good news is identified for females than males, but 'bad' news has less of an impact on the young and older age groups. Caution should be exercised in basing policy on such sentiments.
\end{abstract}

Keywords: Attitudes; news; Olympic Games; compositional time-series.

JEL codes: C25, D12, L83 


\section{Introduction}

Hosting the Olympics, and the Summer Olympics in particular, involve large scale public investment. Despite this there is competition to host the Olympics. In the case of the London 2012 Olympics the rationale was set out in Game Plan and 'despite the difficulty in quantifying the impact, there appears to be a positive impact for the nation as a whole' [15, p.70].

Most of the economic literature suggests negligible and even negative impacts through crowding out $[4,14,16]$. For example, focusing on the 1984 Los Angeles and 1996 Atlanta Summer Olympics Baade and Matheson [5] found that the (expost) impact on unemployment in both regions was entirely transitory and concluded that long-run changes to steady-state equilibrium were only possible when new infrastructure and facilities were appropriate for the present and future economy. Madden [31] and Giesecke and Madden [20] concluded that initial ex-ante assessments of the impact of the 2000 Sydney Olympics over-estimated the financial gain because the assumptions relating to induced tourism and the responsiveness of the labour market were overly optimistic.

It is partly because of such difficulties that the claim that major sporting events such as the Olympics can provide important intangible benefits has emerged. For example, hosting such events, or success in them, appears to influence optimism in stock markets $[2,17,28,30,42]$ and subjective well-being $[29,40]$. 
In this study, therefore, it is hypothesised that the same sort of impact of news stories could take place during the preparation stage, and consequently the impact of the two most significant Olympic-related stories that occurred during the run-up to London 2012 are examined. These are news of the substantial increase in cost (March 2007) and the success of the British team during the Beijing 2008 Olympics (August 2008). In respect of these issues, initial estimates by the London Organising Committee placed the total cost of hosting the event at $£ 2.4$ billion. However, in March 2007 it was announced that the total cost had almost quadrupled to just under $£ 9.3$ billion.

In the 2008 Beijing Olympics, the British team won 47 medals, including 19 gold, finishing fourth in the medal table, which was a position that was widely unexpected. Confirmation of better than expected performance is provided by the UK Sporting Preferences Survey 2008 [41], who carried out a pre-Beijing survey asking interviewees where in the Olympic medal table they expected the British team to finish. Only 16 per cent of respondents expected the team to finish in the top five. Further verification is provided by a number of econometric models of the determination of medal counts that generally, and in some cases significantly, underpredicted Britain's medal total [18].

This paper examines the changes in the stated monthly support, as measured as a scale variable, for hosting the 2012 games over time. The impacts of these news events are revealed using compositional time-series techniques that, unlike traditional time-series methods, account for the restrictions placed on the data by the use of a scale in eliciting opinion: in other words, that increases in the proportion of one category of response must be matched by reductions elsewhere on the scale. 


\section{Data and Methodology}

This study uses data from the Taking Part Survey (TPS), commissioned by the Department for Culture, Media and Sport (DCMS). The TPS is a continuous (repeated cross-section, but not a panel) national survey of England which was first undertaken in 2005. In this study, data from the first four waves (2005-6, 2006-7, 2007-08 and 2008-09) are employed, generating over 35,000 usable observations.

The TPS provides a unique opportunity to investigate attitudes and behaviour during the preparation stage of the Olympics, as these waves of the survey have a question specifically asking respondents about their feelings towards the UK hosting the 2012 Summer Olympic Games in London. Five options are presented in a measurement scale: strongly supportive $\left(x_{5 t}\right)$, slightly supportive $\left(x_{4 t}\right)$, neither supportive or against $\left(x_{3 t}\right)$, slightly against $\left(x_{2 t}\right)$, strongly against $\left(x_{1 t}\right)$.

Importantly, the survey is administered in such a way that there are enough observations to consider month-by-month variations in public attitudes, rather than simple wave-specific (yearly) effects. This provides a rich data set that allows a more precise investigation of the relationship between Olympic-related news and public opinion. A preliminary view of the attitudes and motivation of respondents on a month-by-month basis (from January 2006 to March 2009) is presented in Figure 1.

FIGURE 1 [about here] 
Panel (a) shows the proportion of respondents against the UK hosting the 2012 Olympics and Panel (b) the proportion of respondents who are supportive. Visual inspection suggests the presence of longer term trends though there appears to be a spike in the data associated with cost overruns for those against hosting the games in Panel (a). Likewise in Panel (b) against a declining trend, a spike in support for hosting the Games might be seen to follow from August 2008. To unpick these effects more forensically, a time-series analysis is undertaken, taking account of the compositional nature of the data as implied by the measurement scale.

\subsection{Compositional Data}

A compositional data set is one in which the $n$ observations on $d+1$ variables, denoted $\mathbf{x}_{i}=\left(x_{i 1}, x_{i 2}, \ldots, x_{i n}\right)^{\prime}, i=1,2, \ldots, d+1$, are such that $\mathbf{x}_{i}>0$ and $\mathbf{x}_{1}+\mathbf{x}_{2}+\ldots+\mathbf{x}_{d+1}=\mathbf{1}$, where $\mathbf{1}$ is the unit vector, here of dimension $d+1$. The matrix $\mathbf{X}^{(d)}=\left[\begin{array}{llll}\mathbf{x}_{1} & \mathbf{x}_{2} & \ldots & \mathbf{x}_{d}\end{array}\right]$ then lies in the $d$-part simplex, $S^{d}$, with $\mathbf{x}_{d+1}=\mathbf{1}-\sum_{i=1}^{d} \mathbf{x}_{i}$. being the vector of 'fill-up' values: $\mathbf{X}=\left[\begin{array}{ll}\mathbf{X}^{(d)} & \mathbf{x}_{d+1}\end{array}\right]$ is thus the complete data matrix.

Because of the difficulties of analysing $\mathbf{X}$ within the simplex sample space, Aitchison [1] proposed mapping $\mathbf{X}^{(d)}$ from $S^{d}$ to the $d$-dimensional real space $R^{d}$ and then examining the statistical properties of the transformed data within $\mathbb{R}^{d}$. Several transformations have been proposed for doing this, the most popular being the additive-logratio transformation defined as 
$\mathbf{Y}=\left[\begin{array}{llll}\mathbf{y}_{1} & \mathbf{y}_{2} & \ldots & \mathbf{y}_{d}\end{array}\right]=a_{d}\left(\mathbf{X}^{(d)}\right)=\left[\begin{array}{ll}\log \left(\frac{\mathbf{x}_{1}}{\mathbf{x}_{d+1}}\right) & \left.\log \left(\frac{\mathbf{x}_{2}}{\mathbf{x}_{d+1}}\right) \quad \ldots \quad \log \left(\frac{\mathbf{x}_{d}}{\mathbf{x}_{d+1}}\right)\right]\end{array}\right.$

The inverse transformation, known as the additive-logistic, is

$$
\begin{aligned}
\mathbf{X}^{(d)}= & a_{d}^{-1}(\mathbf{Y})=\left[\begin{array}{llll}
\frac{\exp \left(\mathbf{y}_{1}\right)}{1+\sum_{i=1}^{d} \exp \left(\mathbf{y}_{i}\right)} & \frac{\exp \left(\mathbf{y}_{2}\right)}{1+\sum_{i=1}^{d} \exp \left(\mathbf{y}_{i}\right)} & \ldots & \frac{\exp \left(\mathbf{y}_{d}\right)}{1+\sum_{i=1}^{d} \exp \left(\mathbf{y}_{i}\right)}
\end{array}\right] \\
\mathbf{x}_{d+1} & =\frac{1}{1+\sum_{i=1}^{d} \exp \left(\mathbf{y}_{i}\right)}
\end{aligned}
$$

Thus, an analysis which is difficult in the 'awkward' sample space $S^{d}$ may be transformed using $a_{d}$ to $\mathrm{R}^{d}$, in which more tractable statistical analyses may be performed before using $a_{d}^{-1}$ to return to the original variables.

\section{Results}

Consider the case where the $\mathbf{x}_{i}$ are time series of proportions, and are now written $\mathbf{x}_{i}=\left(x_{i 1}, x_{i 2}, \ldots, x_{i T}\right)^{\prime}$, so that there are $T$ observations available. Accordingly, denote $\mathbf{X}_{t}$ to be the th row of $\mathbf{X}$ and $\mathbf{Y}_{t}$ to be the th row of the additive-logratio transformed data matrix $\mathbf{Y}$. Brunsdon and Smith [9] consider modelling $\mathbf{Y}_{t}$ as a vector ARMA process but other frameworks are available in which covariates and trend functions may be introduced: see Mills $[32,33,34]$ for a variety of examples. It should be emphasised that the modelling is invariant to the choice of fill-up value, so that any of the $x_{i}$ can be chosen. 
The survey data available thus constitute a compositional time series of dimension $d+1=5$ of proportions from January 2006 to April 2009, a total of 40 observations, as defined earlier. They are plotted as Figure 2. Attention focuses on the two 'events' of the March 2007 announcement of the increase in the cost of staging the Olympics and the success of Team GB at the Beijing Olympics of August 2008. These events are modelled as dummies, taking zeros everywhere except that $d_{-}{ }_{07}$ takes the value 1 in March 2007 and $d_{-}$08 ${ }_{t}$ takes the value 1 in August 2008.

\section{Figures 2 and 3 [about here]}

The proportions were additive-logratio transformed using $x_{5 t}$ as the fill-up value, thus defining $y_{i t}=\log \left(x_{i t} / x_{5 t}\right), i=1, \ldots, 4$. These ratios are shown in Figure 3 and were then modelled as a dummy-augmented vector $\mathrm{AR}(1)$ process, with this order being selected by a variety of criteria, the fitted model being estimated as 


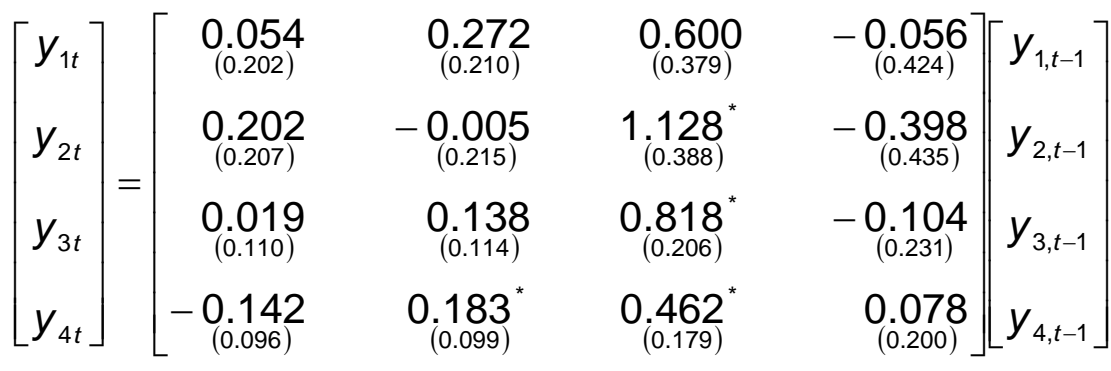

$$
\begin{aligned}
& +\left[\begin{array}{ccc}
0.303 & -0.285 & -1.022^{*} \\
(0.185) & (0.182) & (0.327) \\
0.283 & -0.266 & -1.119^{*} \\
(0.189) & (0.186) & 0.335) \\
-0.063 & -0.381^{*} & 0.167 \\
(0.101) & (0.099) & d_{-} 07 t \\
0.037 & -0.280^{*} & -0.164 \\
(0.087) & (0.081) & d_{-} 08_{t} \\
1
\end{array}\right]+\left[\begin{array}{c}
u_{1 t} \\
u_{2 t} \\
u_{3 t} \\
u_{4 t}
\end{array}\right]
\end{aligned}
$$

Standard errors are in parentheses and coefficients significant at the $10 \%$ level are indicated by an asterisk. Few coefficients are individually significant and the model is clearly over-parameterized, making interpretation problematic. The following restricted model was therefore developed. 


$$
\begin{aligned}
& {\left[\begin{array}{l}
y_{1 t} \\
y_{2 t} \\
y_{3 t} \\
y_{4 t}
\end{array}\right]=\left[\begin{array}{cccc}
- & - & 0.956 & - \\
& & 0.029) & \\
- & - & \underset{(0.094)}{1.095} & - \\
- & - & 0.956 & - \\
- & - & 0.601 & -
\end{array}\right]\left[\begin{array}{c}
y_{1, t-1} \\
y_{2, t-1} \\
y_{3, t-1} \\
y_{4, t-1}
\end{array}\right]} \\
& +\left[\begin{array}{rrr}
0.377 & -\underset{(0.142)}{0.290} & -{ }_{(0.026)}^{1.418} \\
0.377 & -0.290 & -\underset{(0.045)}{0.300} \\
- & -\underset{(0.097)}{0.397} & - \\
- & -0.290 & -\underset{(0.022)}{0.201}
\end{array}\right]\left[\begin{array}{c}
d_{-} 07_{t} \\
1
\end{array}\right]\left[\begin{array}{c}
u_{1 t} \\
u_{2 t} \\
u_{3 t} \\
u_{4 t}
\end{array}\right]
\end{aligned}
$$

The restrictions are either coefficient omissions or cross-equation coefficient equalities: in total a set of 19 restrictions are imposed, with an accompanying likelihood ratio statistic of 13.16 , so the set is certainly acceptable. The nine coefficients that are freely estimated are all significant at less than the $1 \%$ level. The system is being driven by $y_{3}=\log \left(x_{3} / x_{5}\right)$, while both events appear to have had significant effects on the system, with $y_{1}$ and $y_{2}$ being positively affected by the March 2007 event, and $y_{3}$ and $y_{4}$ being unaffected, while all ratios are negatively affected by the August 2008 event, movements that can clearly be seen in Figure 2. The system is more interpretable if log-proportions are considered. The model (4) can thus be written as

$$
\begin{aligned}
& \log x_{1 t}=0.96 \log x_{3, t-1}+\Delta \log x_{5 t}+0.04 \log x_{5, t-1}+0.38 d_{-} 07_{t 6}-0.29 d_{-} 08_{t}-1.42 \\
& \log x_{2 t}=1.09 \log x_{3, t-1}+\Delta \log x_{5 t}-0.09 \log x_{5, t-1}+0.38 d_{-} 07_{t}-0.29 d_{-} 08_{t}-1.30
\end{aligned}
$$


$\log x_{3 t}=0.96 \log x_{3, t-1}+\Delta \log x_{5 t}+0.04 \log x_{5, t-1}-0.40 d_{-} 08_{t}$

$\log x_{4 t}=0.60 \log x_{3, t-1}+\Delta \log x_{5 t}-0.40 \log x_{5, t-1}-0.29 d_{-} 08_{t}-0.20$

Focusing on the impact of the two events, it can be seen that $x_{1}$ and $x_{2}$ were positively affected by the March 2007 event, $x_{3}$ and $x_{4}$ were unaffected and, by the nature of the composition, $x_{5}$ was negatively affected. In other words, those proportions already hostile to the Olympics increased in response to the announcement that the games would be more expensive, those proportions that were indifferent or mildly supportive remained the same, while the proportion strongly in favour declined somewhat. Again these shifts can be seen in Figure 2.

The response to the August 2008 event was that the first four proportions all declined in size, in particular those who were indifferent, while the proportion most supportive increased in size, shifts that can also be seen in Figure 2. The performance of the British team in the Beijing Olympics thus had a pronounced positive influence on support for the London Olympics. The first row of Table 1 provides estimates of the changes in these proportions (measured in percentage points) obtained via simulation of the model. Thus the March 2007 event increased $x_{1}$ and $x_{2}$ by 2.3 and 2.4 percentage points respectively, with $x_{5}$ being correspondingly reduced by 4.7 points. The August 2008 event led to a decline of 0.5, 0.6, 4.8 and 1.5 percentage points for the first four categories, with $x_{5}$ correspondingly increasing by 7.4 points. Table 1 also presents analogous results at a disaggregated level by analysing the geographic groups 'excluding London (Ex 
Ldn)', 'north', 'south' and 'midlands and east (M\&E)', the age groups 16-29, 30-44, 45-59 and 60+, and males and females. For brevity, details of the models are omitted.

\section{TABLE 1 [about here]}

The results show some considerable variation in impact. Broadly speaking, the good news of Olympic success produces relatively large increases in strong support for the Olympics, as the above literature review might suggest. However, this is not uniform. It is most prevalent in the younger age-groups and females and more so away from London. This might be because the Olympics reaches an audience that is usual for sport, that of young males, but it also attracts female support because, unlike most professional sports, it is not male dominated. That London and the south seem to respond less to success could be indicative of the concerns of residents of the host areas noted earlier. Interestingly, the impact of the cost overruns being announced in March 2007 are accompanied by increases in support for the Games in the north and for females, which might suggest that, for the reasons noted above, the benefits of hosting the games exceed the costs for these groups. In general, however, for males and those of middle age there is a clear shift away from support for the Games in the context of bad news.

\section{Conclusion}

Although differences in sentiment play a part in the evolving economic valuation of companies through the stock market, it is less well known how 'news' affects sentiment towards major public investments like the Olympics. In this paper the 
relationship between attitudes towards the Olympics, the bad news associated with an increase in the cost of provision and the good news associated with Team GB's medal success in 2008 are analysed. Using a unique data set and a novel eventstudy approach that involves compositional time-series analysis enables us to identify that 'good' news affects sentiment much more than 'bad' news, but that the distribution of such sentiment varies widely. We identify that the good news of Olympic success produces large increases in 'strong support' towards the Olympics particularly for younger age groups, females and non-London residents. For males and those of middle-age, there is a general reduction in sport for the Games in the context of bad news. 


\section{References}

[1] J. Aitchison, The statistical analysis of compositional data (with discussion), J. of the J. R. Stat. Soc. B. 44 (1982), pp. 139-177.

[2] J.K. Ashton, B. Gerrard, B. and R. Hudson, Economic Impact of national Sporting Success: Evidence from the London Stock Exchange, Appl. Econ. Let. 10 (2003), pp.783-785.

[3] G. Atkinson, S. Mourato, S. Szymanski and E. Ozdemiroglu, Are we willing to pay enough to 'back the bid'?: Valuing the intangible impacts of London's bid to host the 2012 Summer Olympic Games, Urban Stud. 45 (2008), pp. 419444.

[4] R.A. Baade, The economic impact of mega-sporting events, in Handbook of the Economics of Sport, W. Andreff W and S. Szymanski, eds., Edward Elgar, Cheltenham, 2007, pp. 177-182.

[5] R.A. Baade and V. Matheson, Bidding for the Olympics: fool's gold? In Transatlantic Sport: the comparative economics of North America and European Sports, C.P. Barros, M. Ibrahimo and S. Szymanski, eds., Edward Elgar, London, 2002, pp. 127-151.

[6] N.J. Balmer, A.M. Nevill and A.M. Williams, Home advantage in the Winter Olympics (1908-1998), J. Sport Sci. 19 (2001), pp.129-139.

[7] BBC, London 2012 Olympics deliver record viewing figures for BBC, 2012. Available at http://www.bbc.co.uk/mediacentre/latestnews/2012/olympic-viewing-figs.html

[8] A. Bernard and M. Busse, Who wins the Olympics? Economic resources and medal totals. Rev. Econ. Statistics 86 (2004), pp. 413-417.

[9] T.M. Brunsdon and T.M.F. Smith, Time series analysis of compositional data, J. Official Stat., 14 (1998), pp. 237-253. 
[10] R. Cashman and A. Hughes, Staging the Olympics: The Event and its Impact.UNSW Press, Sydney, 1999.

[11] J. Crompton, Economic Impact Analysis of Sports facilities and Events: Eleven sources of misapplication, J. Sports Manag. 9 (1995), pp. 14-35.

[12] J. Crompton, Beyond economic impact: an alternative rationale for the subsidy of major league sports facilities, J. Sports Manag. 18 (2004), pp. 4058.

[13] J. Crompton, J. Economic Impact Studies: Instruments for Political Shenanigans? J. travel Res. 45 (2006), pp. 67-82.

[14] P. Dawson, Economics of the Olympics, in The Oxford Handbook of Sports Economics Volume 1: The Economics of Sports, L. Kahane and S. Shmanske, eds., Oxford University Press, New York, 2012, pp.425-448.

[15] DCMS/Strategy Unit, Game Plan: A strategy for delivering government's sport and physical activity objectives, London, 2002.

[16] P. Downward, T. Dejonghe and A. Dawson, Sports Economics: Theory, Evidence and Policy, Elsevier, London, 2009.

[17] P. Downward, T. Nishio and C. Lim, C, Olympics Host City Selection and its impact on Stock markets, J. Hosp. To. 1 (2010), pp. 35-50.

[18] D. Forrest, I. Sanz and J.D. Tena, Forecasting national team medal totals at the Summer Olympic Games, Int. J. Forecasting 26 (2010), pp. 576-588.

[19] S. Frawley and A. Cush, Major sports events and participation legacy: the case of the 2003 Rugby World Cup, Manag. Leisure 16 (2011), pp. 65-76. 
[20] J. Giesecke and J. Madden, J, The Sydney Olympics, Seven years on: an expost dynamic CGE assessment. Centre of Policy Studies Monash University Working Paper G-168, 2007.

[21] M. Green and B. Houlihan, Elite Sport Development: Policy Learning and Political Priorities, Routledge, London, 2005.

[22] C. Guala, To bid or not to bid: Public opinion before and after the Games: The case of Turin, in The Olympic Legacy: People, place, enterprise, J. Kennell, C. Bladon and E. Booth, eds., University of Greenwich, London, 2009.

[23] H. Hiller and R. Wanner, Public opinion in host Olympic cities: The case of the 2010 Vancouver Winter Games, Sociology 45 (2011), pp. 883-899.

[24] A. Hindson, B. Gidlow and C. Peebles, The 'trickle-down' effect of top-level sport: myth or reality? A cast study of the Olympics, Aust. J. Leisure Recreation 4 (1994), pp. 16-24.

[25] K. Hogan and K. Norton, The 'price' of Olympic gold. J. Sci. Med. Sport 3 (2000), pp. 203-218.

[26] B. Houlihan and M. Green (eds.), Comparative Elite Sport Development: Systems, Structures and Public Policy. Oxford, Butterworth-Heinemann, 2008.

[27] IOC, Games of the XXIX Olympiad, Beijing 2008: Global Television and the Online Media Report, 2009. Available at: http://www.olympic.org/Documents/IOC Marketing/Broadcasting/Beijing 2008 Global Broadcast Overview.pdf

[28] G. Kavetsos and S. Szymanski, Olympic Games, terrorism and their impact on the London and Paris stock exchanges, Rev. Econ. Polit. 118 (2008), pp. 189-206. 
[29] G. Kavetsos and S. Szymanski, National well-being and international sports events, J. Econ. Psychol. 31 (2010), pp. 158-171.

[30] M. Leeds,J. Mirikitani and D. Tang, Rational exuberance? An event analysis of the 2008 Olympics announcement, Int. J. Sport Financ. 4 (2009), pp. 5-15.

[31] J. Madden, Economic and fiscal impacts of mega sporting events: a general equilibrium assessment, Public Financ. Manage. 6 (2006), pp. 346-394.

[32] T.C. Mills, Modelling compositional data in economics, Indian Econ. J. 55 (2007), pp. 99-115.

[33] T.C. Mills, Forecasting obesity trends in England, J. R. Stat. Soc. A. 172 (2009), pp.107-117.

[34] T.C. Mills, Forecasting compositional time series, Qual. Quant. 44 (2010), pp. 673-690.

[35] B. Mihalik, Host population perceptions towards the 1996 Atlanta Olympics: Benefits and liabilities, in The legacy of the Olympic Games 1984-2000, M. De Moragas, C. Kennett, C and N. Puig, eds., International Olympic Committee, Lausanne, 2003.

[36] J.R.B. Ritchie and C.E. Aitken, OLYMPULSE II - evolving resident attitudes towards the 1988 Olympic Winter Games, J. Travel Res. 23 (1985), pp. 28-33.

[37] J.R.B. Ritchie and M.M. Lyons, OLYMPULSE IV - A post-event assessment of resident reaction to the XVth Olympic Winter Games, J. Travel Res. 28 (1990), pp. 14-23.

[38] B. W. Ritchie, R. Shipway and B. Cleeve, Resident perceptions of megasporting events: a non-host city perspective of the 2012 London Olympic Games, J. Sport Tourism 14 (2009), pp. 143-167. 
[39] S. Shibli, C. Gratton and J. Bingham, J., A forecast of the performance of Great Britain and Northern Ireland in the London 2012 Olympic Games, Manag. Leisure 17 (2012), pp. 274-290.

[40] B. Süssmuth, M. Heyne and W. Maennig, Induced civic pride and integration, Oxford B. Econ. Stat., 72 (2010), pp. 202-220.

[41] UK Sport, UK Sporting Preferences Survey 2008.

[42] N. Veraros, E. Kasimati and P. Dawson, The 2004 Olympic Games announcement and its effect on the Athens and Milan stock exchanges, Appl. Econ. Lett. 11 (2004), pp. 749-753.

[43] H. Walton, A. Longo and P. Dawson, Contingent valuation of 2012 London Olympics: A regional perspective, Journal of Sports Economics 9 (2008), pp. 304-317. 
Figure 1: Feelings Towards the Olympics

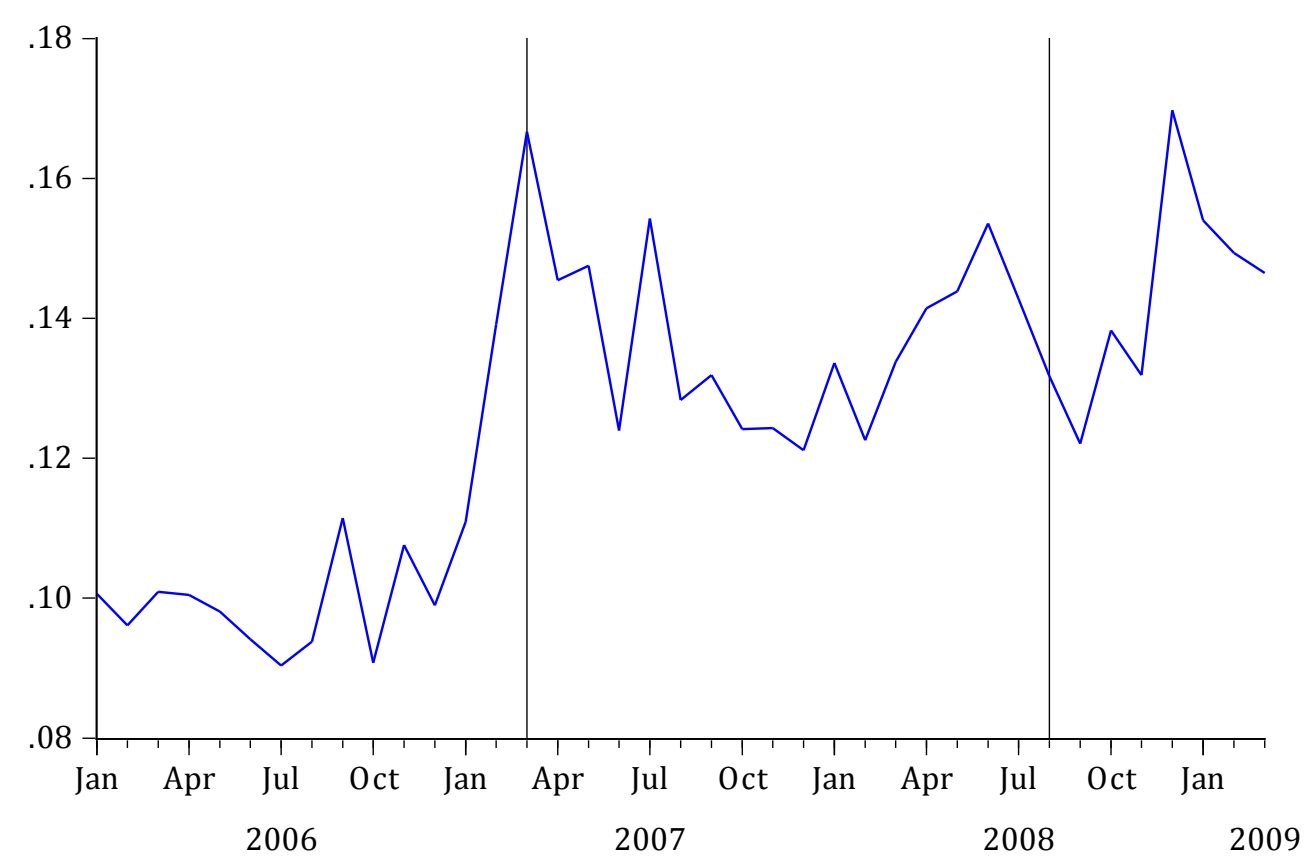

Panel (a): Slightly or Strongly Against

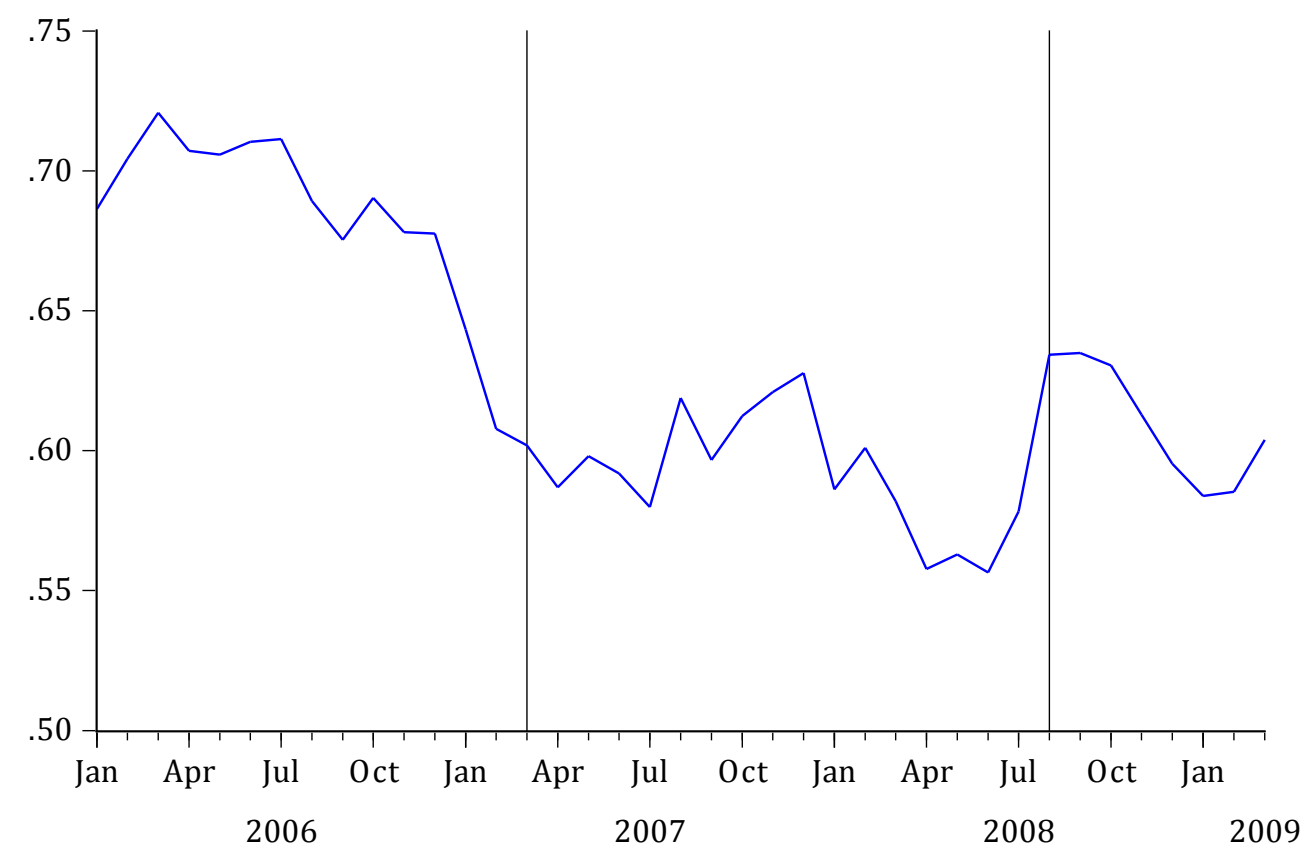

Panel (b): Slightly or Strongly Supportive 
Figure 2 Proportions having various levels of support for the London Olympics (overall)

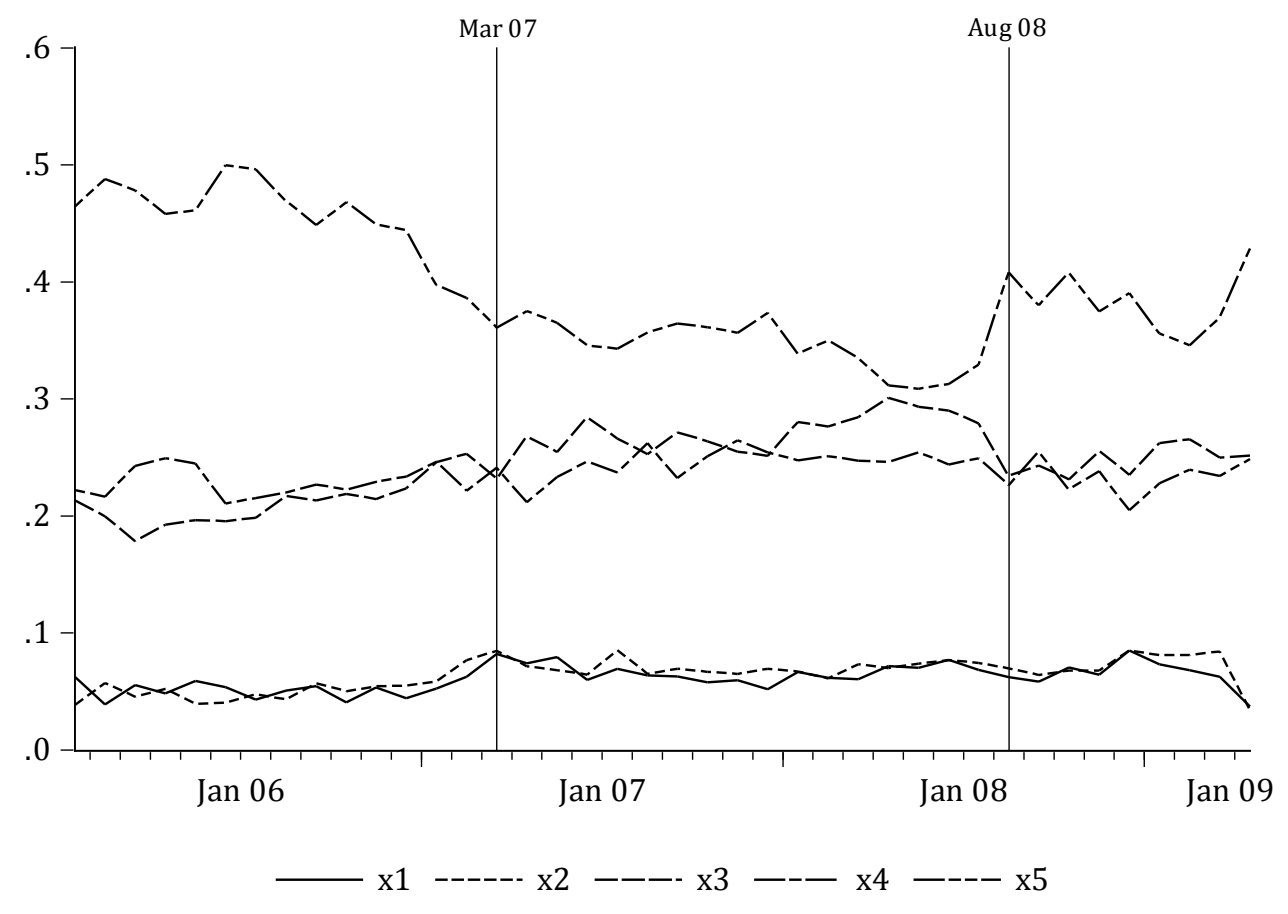


Figure 3 Additive log-ratios of proportions

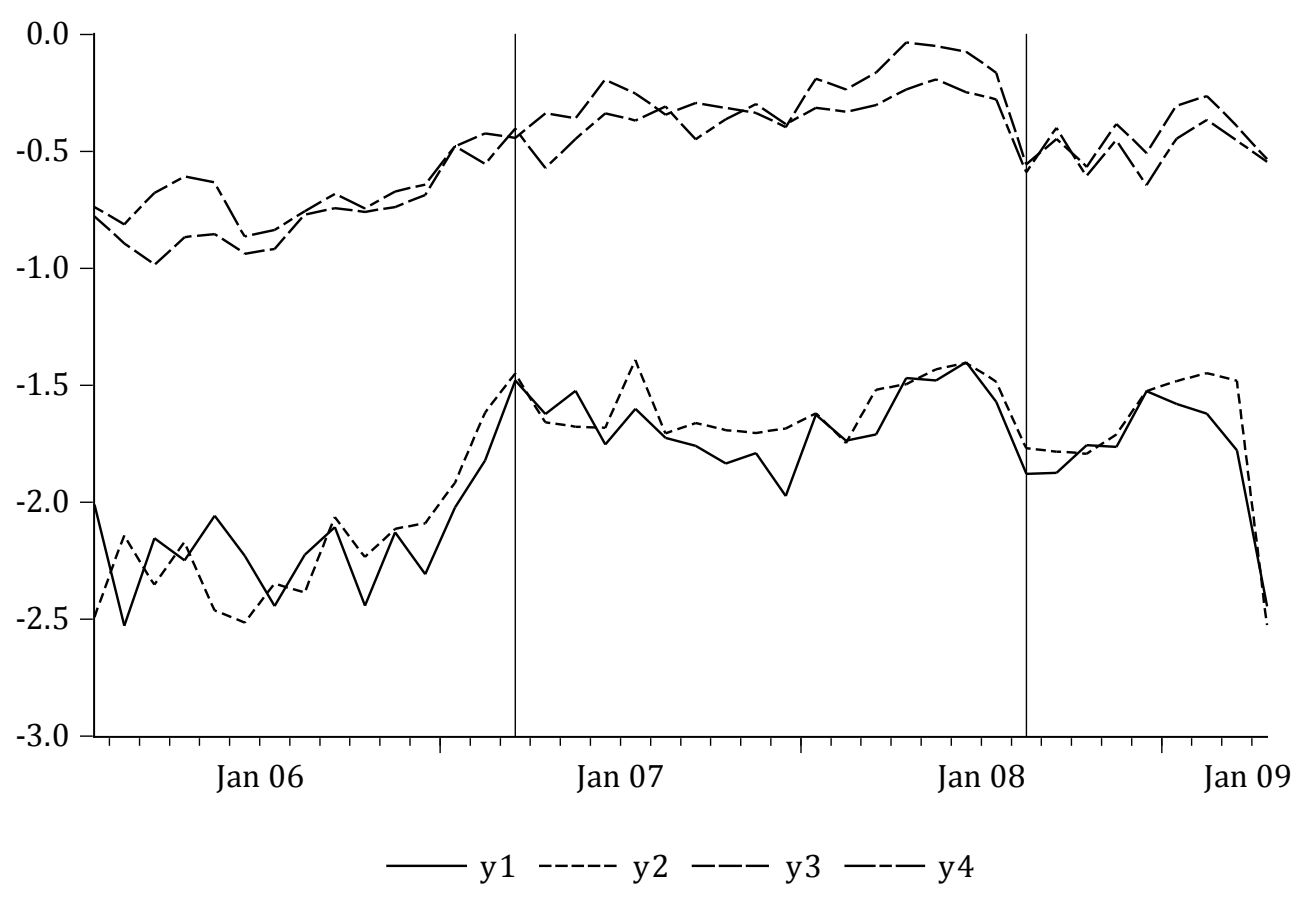


Table 1 Change in support in response to the two events (percentage points)

\begin{tabular}{l|rrrrr|rrrrr}
\hline \multicolumn{7}{c}{ March 2007} \\
\multicolumn{1}{l}{$x_{1}$} & $x_{2}$ & $x_{3}$ & $x_{4}$ & $x_{5}$ & $x_{1}$ & $x_{2}$ & $x_{3}$ & $x_{4}$ & $x_{5}$ \\
\hline All & +2.3 & +2.4 & 0 & 0 & -4.7 & -0.5 & -0.6 & -4.8 & -1.5 & +7.4 \\
Ex Ldn & +2.2 & +2.7 & 0 & 0 & -4.9 & -0.8 & -0.9 & -5.4 & -2.3 & +9.4 \\
North & 0 & +2.7 & -6.4 & 0 & +3.7 & -1.0 & -2.2 & -5.4 & -5.1 & +13.7 \\
South & 0 & 0 & 0 & 0 & 0 & 0 & 0 & -4.0 & 0 & +4.0 \\
M\&E & +1.7 & +1.4 & 0 & 0 & -3.1 & -0.5 & -0.2 & -5.7 & -2.5 & +8.9 \\
16-29 & 0 & 0 & 0 & 0 & 0 & 0 & 0 & -10.0 & -1.3 & +11.3 \\
$30-44$ & +2.2 & 0 & 0 & 0 & -2.2 & -0.7 & 0 & -3.2 & -2.1 & +6.0 \\
$45-59$ & +2.8 & 0 & 0 & 0 & -2.8 & 0 & 0 & -3.7 & -2.7 & +6.4 \\
$60+$ & 0 & 0 & -5.1 & 0 & +5.1 & -1.9 & 0 & 0 & 0 & +1.9 \\
Male & +5.0 & +3.1 & 0 & 0 & -8.1 & 0 & -1.5 & 0 & 0 & +1.5 \\
Female & 0 & 0 & -3.8 & 0 & +3.8 & -0.6 & 0 & -6.1 & -3.1 & +9.8 \\
\hline
\end{tabular}

